\title{
ANALISIS VALIDITAS TERHADAP PENGEMBANGAN PENUNTUN PRAKTIKUM IPA BERBASIS MODEL PEMBELAJARAN COLLABORATIVE TEAMWORK LEARNING (CTL) UNTUK SISWA SMPN SE KECAMATAN BONJOL KABUPATEN PASAMAN
}

(Analysis of the validity of the Development of Scientific Practicum Developers Based on Collaborative Teamwork Learning (CTL) Learning Models for Students SMPN, Bonjol Sub District, Pasaman District)

\section{Oleh : Ennike Gusti Rahmi*) Rini Silvina*) \\ Email: ennikerahmi@gmail.com}

*)Dosen STKIP Ahlussunnah Bukittinggi

\begin{abstract}
Teachers carry out practical activities not yet using practicum guides. Practical activities carried out by teachers have tended to only provide instruction. This is because the school does not yet have a practical guidebook. Difficulties are also faced by students, because students do not know what practical activities will be carried out and cause a lack of preparation of students in practicing. This study aims to produce a practical guide based on Collaborative Teamwork Learning on life organization system material for class VII students in SMP in Bonjol Subdistrict, Pasaman Regency, which is valid. The type of development research (Develpomental research), the development model in the form of a descriptive procedural model which outlines the steps that must be followed to produce the product. The data collection technique used was a validation sheet questionnaire. The validity of the Collaborative Teamwork Learning practicum test conducted by material experts and media experts from the validation results obtained a percentage value based on aspects of didactic requirements $83.33 \%$, aspects of construct requirements $84.72 \%$, aspects of technical requirements $82.29 \%$ and aspects of language requirements is $89.58 \%$. The overall validity test results obtained a percentage value of $84.98 \%$ with valid criteria. based on the results of the validity test the practicum guide analysis developed was valid for use in practical activities.
\end{abstract}

Key words: Analysis, validity, Development of Scientific Practicum Developers, Collaborative Teamwork Learning (CTL) Learning Models

\section{PENDAHULUAN}

Ilmu pengetahuan alam (IPA) adalah suatu ilmu pembelajaran yang berkaitan dengan kehidupan sehari-hari atau alam, sehingga Ilmu Pengetahuan Alam (IPA) bukan hanya penguasaan kumpulan pengetahuan yang berupa fakta-fakta, konsep-konsep atau prinsip-prinsip saja tetapi juga merupakan suatu proses penemuan. Pembelajaran IPA tidak dapat dipahami jika hanya diajarkan secara hafalan. Oleh karena itu, diperlukan suatu kegiatan yang akan meningkatkan pemahaman siswa dalam pembelajaran IPA yaitu melalui kegiatan praktikum. Suatu kegiatan praktikum dapat dilakukan oleh siswa di laboratorium atau di lapangan.

Praktikum Menurut Rahayuningsih (2005) dalam Susantini (2012:102) merupakan bagian integral dari kegiatan belajar mengajar. Praktikum menjadi sarana pengenalan bahan dan peralatan yang semula dianggap abstrak menjadi lebih nyata sehingga siswa lebih memahami konsep-konsep materi 
pembelajaran. Pembelajaran dengan praktikum sangat efektif untuk mencapai seluruh ranah pengetahuan secara bersamaan, antara lain melatih agar teori dapat diterapkan pada permasalahan yang nyata (kognitif), melatih perencanaan kegiatan secara mandiri (afektif) dan melatih penggunaan instrument tertentu (psikomotor).

Hal tersebut menunjukkan betapa pentingnya peranan praktikum dalam pencapaian tujuan pembelajaran, dimana kegiatan praktikum dapat menunjang pengetahuan dan pemahaman siswa terhadap materi pelajaran biologi, sehingga kegiatan praktikum itu sudah menjadi komponen dari pembelajaran biologi. Selain itu, kegiatan praktikum dapat mengembangkan keterampilan dasar bereksperimen siswa.

Kegiatan praktikum memerlukan buku petunjuk praktikum yang akan mempermudah melakukan kegiatan praktikum yaitu penuntun praktikum. dalam suatu penuntun praktikum terdapat $\mathrm{SK}, \mathrm{KD}$, tujuan pembelajaran, dasar teori, alat dan bahan, langkah kerja, hasil pengamatan, pembahasan, kesimpulan, pertanyaan dan daftar pustaka (Rohman dan Amri, 2013: 97-98).

Berdasarkan observasi beberapa SMP di Kecamatan Bonjol, banyak kendala yang dialami guru dalam memaksimalkan kegiatan praktikum yaitu tidak adanya buku penuntun praktikum IPA di sekolah tersebut. Praktikum IPA yang dilakukan hanya berpedoman pada lembar kegiatan praktikum yang ada di buku paket yang dimiliki siswa. Hal ini terkadang menyulitkan guru untuk mencari-cari terlebih dahulu kegiatan praktikum yang tepat diterapkan di sekolah. Guru masih mengalami masalah untuk melakukan praktikum tentang topik-topik tertentu, tidak semua konsep IPA dapat diajarkan dengan praktikum karena keterbatasan alat dan bahan yang tersedia.

Guru melakukan kegiatan praktikum belum menggunakan penuntun praktikum, terutama untuk materi sistem organisasi kehidupan. Untuk memahami materi ini, banyak diperlukan kegiatan praktikum. Kegiatan praktikum yang dilakukan guru selama ini cenderung hanya memberikan instruksi saja. Hal ini dikarenakan bahwa sekolah tersebut belum memiliki buku penuntun praktikum khusus yang merangkum kegiatan praktikum apa saja yang akan dilaksanakan dalam pembelajaran IPA di SMP tersebut.

Kesulitan juga dihadapi siswa, karena siswa tidak mengetahui kegiatan praktikum apa yang akan dilaksanakan dan menyebabkan kurangnya persiapan siswa dalam melakukan praktikum. Oleh karena itu perlu dikembangkan suatu penuntun praktikum yang berisi materi IPA terpadu dan dapat meningkatkan aktivitas dan hasil belajar siswa dalam kegiatan praktikum.

Dalam kegiatan praktikum dibutuhkan keterampilan proses bagi siswa. Salah satu model pembelajaran yang dapat menunjang peningkatan keterampilan proses siswa adalah model pembelajaran Collaborative Teamwork Learning (CTL). Model pembelajaran Collaborative Teamwork Learning (CTL) merupakan model pembelajaran yang menekankan kinerja dan kekompakan tim yang dibentuk siswa dalam memecahkan permasalahan yang diberikan guru sehingga diharapkan praktikum yang dilaksanakan peserta didik dapat menunjang kerja sama siswa dalam kelompok serta seluruh siswa dapat berperan aktif pada saat pelaksanaan kegiatan praktikum (Jiwa, 2013: 2).

Kelebihan model Collaborative Teamwork Learning (CTL) adalah dapat meningkatkan keaktifan dan kekompakan siswa saat melakukan praktikum bersama teman sekelompoknya. Model ini menuntut siswa untuk bekerjasama dalam kelompok yang telah ditentukan dan bertanggung jawab atas kelompok tersebut dalam mengerjakan tugas. Sehingga siswa dapat mengembangkan ide, pendapat atau pikiran tentang materi yang dipraktekan.

Dalam hal ini peneliti melakukan pengembangkan penuntun praktikum berbasis model pembelajaran 
Collaborative Teamwork Learning (CTL) pada materi sistem organisasi kehidupan Sehingga pengembangan penuntun praktikum diharapkan mampu memotivasi peserta didik untuk mengasah kemampuan menganalisa, mengidentifikasi, dan pemecahan masalah. Tujuan penelitian ini mengetahui tingkat kevaliditasan penuntun praktikum berbasis model pembelajaran Collaborative Teamwork Learning (CTL) pada materi system organisasi kehidupan kelas VII agar layak digunakan dalam kegiatan pratikum.

\section{METODE PENELITIAN}

Penelitian ini model yang digunakan adalah model 4D (four-D models). Pengembangan four-D models terdiri dari 4 tahap utama yaitu:

1) define (pendefenisian), 2) desaign (peancangan), 3) develop (pengembangan) dan 4) disseminate (penyebaran) (Trianto, 2010:93). Pada penelitian ini hanya dilakukan sampai tahap develop saja, karena mengingat berbagai keterbatasan peneliti. Validasi terhadap instrumen penelitian dan penuntun pratikum yang akan digunakan untuk ujicoba kepada ahli media, ahli bahasa dan ahli isi/materi.

Instrumen Validitas berupa lembar validasi penuntun praktikum digunakan untuk mengetahui validitas penuntun praktikum yang dikembangkan. Lembaran validasi ini menggunakan angket berupa daftar pertanyaan yang diberikan kepada validator untuk memberikan respon yang sesuai dengan permintaan pengguna. Angket validasi ini diisi oleh validator dengan kriteria yang telah disediakan.

Instrumen validasi berupa lembar validasi modul pembelajaran yang modifikasi Darmodjo dan Kaligis dalam Widjajayanti (2008). Analisis hasil penelitian yang diberikan validator

Tabel 2. Hasil Validasi Penuntun Praktikum

\begin{tabular}{llll}
\hline No & Aspek Penilaian & Persentase & Kategori \\
\hline 1. & Syarat didaktik & $\mathbf{8 3 , 3 3 \%}$ & Valid \\
\hline 2. & Syarat konstruk & $\mathbf{8 4 , 7 2} \%$ & Valid \\
\hline 3. & Syarat teknis & $\mathbf{8 2 , 2 9 \%}$ & Valid \\
\hline 4. & Syarat bahasa & $\mathbf{8 9 , 5 8 \%}$ & Valid \\
\hline
\end{tabular}

terhadap penuntun praktikum digunakan bentuk item a, b, dan c.

a. Syarat Didaktik

Syarat didaktik berkenaan dengan proses penemuan konsep-konsep yang benar sesuai dengan kurikulum yang berlaku. Kemudian memperhatikan adanya perbedaan individual sehingga penuntun praktikum yang baik itu dapat digunakan untuk mengukur kemampuan siswa.

b. Syarat Konstruksi

Syarat yang berkenaan dengan susunan kalimat, kesederhanaan pemakaian kata-kata dan kejelasan yang pada hakikatnya haruslah tepat guna dalam artian dapat dimengerti siswa.

c. Syarat Teknis

Syarat teknis berkenaan dengan bahasa, tulisan, gambar, dan penampilan penuntun praktikum.

Teknik Analisa Data dilakukan dengan menggunakan teknik persentase, dari data angket yang disusun menurut skala likert.

Setelah persentase diperoleh, dilakukan pengelompokan sesuai kriteria yang dimodifikasi dari Purwanto (2010:82) sebagai berikut:

\section{Tabel 1. Penilaian validitas}

\begin{tabular}{ll}
\hline $90 \%-100 \%$ & Sangat Valid \\
\hline $80 \%-89 \%$ & Valid \\
\hline $60 \%-79 \%$ & Cukup Valid \\
\hline $0 \%-59 \%$ & Tidak Valid \\
\hline Modifikasi Purwanto (2010:82)
\end{tabular}

\section{HASIL}

Berdasarkan uji validitas menggunakan instrumen lembar penilaian validitas diperoleh hasil pada tabel 2 sebagai berikut: 


\begin{tabular}{lll}
\hline Jumlah & $\mathbf{3 3 9 , 9 2}$ & \\
\hline Rata-rata & $\mathbf{8 4 , 9 8 \%}$ & Valid \\
\hline
\end{tabular}

Dari tabel 2 diketahui bahwa nilai rata-rata hasil uji validitas penuntun praktikum berbasis model pembelajaran Collaborative Teamwork Learning (CTL) sebesar 84,98\% dengan kriteria valid sesuai dengan kategori valid menurut Purwanto (2010:82). Hal ini menunjukan bahwa penuntun praktikum yang dihasilkan dalam penelitian ini sudah valid. Baik komponen syarat didaktik, syarat konstruk, syarat teknis dan syarat bahasa. Dan dapat digunakan dengan revisi kecil. Revisi dilakukan sesuai dengan tanggapan dan saran yang diberikan oleh setiap ahli baik yang diberikan secara langsung maupun yang tertulis pada kolom saran. Saran dari tim ahli dan tindakan peneliti seperti yang terdapat pada Tabel 3.

Tabel 3. Saran dan tindakan peneliti

\begin{tabular}{ll}
\hline Saran & Tindakan Peneliti \\
\hline $\begin{array}{l}\text { Untuk petunjuk penggunaan penuntun } \\
\text { praktikum sebaiknya dibedakan antara guru } \\
\text { dan siswa }\end{array}$ & $\begin{array}{l}\text { Membedakan petunjuk penggunaan penuntun } \\
\text { praktikum antara guru dan siswa }\end{array}$ \\
\hline $\begin{array}{l}\text { Untuk gambar kurang jelas pada jaringan } \\
\text { epidermis }\end{array}$ & Memperjelas gambar jaringan epidermis \\
\hline Jenis tulisan terlalu kecil untuk siswa SMP & $\begin{array}{l}\text { Jenis tulisan sudah diperbesar sesuai kebutuhan } \\
\text { siswa SMP }\end{array}$ \\
\hline $\begin{array}{l}\text { Gambar terlalu banyak sehingga sulit } \\
\text { dipahami }\end{array}$ & Gambar sudah dikurangi \\
\hline
\end{tabular}

Saran yang diberikan lebih menekankan pada aspek syarat teknis. Agar siswa lebih mudah memahami penuntun praktikum dengan tulisan yang jelas dan gambar yang bagus.

\section{PEMBAHASAN}

Penuntun praktikum mempunyai peranan penting dalam kegiatan pratikum sehingga dalam pengembangan penuntun praktikum harus tepat dan sesuai dengan kebutuhan siswa agar mampu meningkatkan kemampuan siswa. Proses pengembangan penuntun praktikum memiliki kaidah dan aturan tertentu sesuai dengan model pengembangan yang dilakukan. Model pengembangan 3D modifikasi dari 4D dengan langkah pengembangan define, design, development, dan disseminate. Salah satu tahapan inti adalah melakukan uji validasi. Uji validasi dilakukan sebagai upaya dalam menghasilkan penuntun praktikum yang baik
Berdasarkan hasil analisis instrument lembar penilaian validasi yang dilakukan oleh 3 orang validator yaitu: ahli media, ahli materi dan ahli bahasa diperoleh nilai validasi rata- rata $84,98 \%$ dengan kriteria valid. Hal ini menunjukkan bahwa penuntun praktikum yang dibuat layak digunakan oleh guru dan siswa dalam kegiatan praktikum serta aspekaspek yang diinginkan dalam penelitian ini. Aspek-aspek tersebut meliputi aspek syarat didaktik, syarat konstruk, syarat teknis, dan syarat bahasa.

Ditinjau dari aspek syarat didaktik, penuntun praktikum berbasis model pembelajaran Collaborative Teamwork Learning (CTL) dinyatakan valid oleh oleh validator dengan nilai rata-rata $83,33 \%$. Hal ini menunjukan bahwa kegiatan praktikum yang terdapat di dalam penuntun praktikum sesuai dengan Standar Kompetensi, Kompetensi Dasar, indikator pembelajaran dan tujuan pembelajaran yang akan dicapai. 
Hal ini sesuai dengan Purnamasari (2012) pada pembelajaran dengan metode praktikum dibutuhkan suatu penuntun praktikum. Penuntun praktikum tersebut bertujuan untuk menuntun siswa dalam melakukan praktikum dan membantu guru dalam mencapai standar kompetensi, kompetensi dasar, indikator pembelajaran, tujuan pembelajaran.

Ditinjau dari aspek syarat konstruk penuntun praktikum berbasis model pembelajaran Collaborative Teamwork Learning (CTL) dinyatakan valid oleh oleh validator dengan nilai rata-rata 84,72 $\%$. Hal ini menunjukan bahwa materi yang terdapat di dalam penuntun praktikum tersusun secara sistematis. ini menunjukan bahwa desain penuntun praktikum secara keseluruhan sudah baik dan menarik, tata letak isi, tampilan cover, petunjuk penggunaan praktikum, langkah-langkah penuntun praktikum.

Hal ini sesuai dengan yang dinyatakan oleh Arsyad (2014:20) bahwa gambar berfungsi untuk menarik dan mengarahkan perhatian siswa untuk berkonsentrasi kepada isi pelajaran yang berkaitan dengan makna gambar yang ditampilkan dan menyertai teks materi pelajaran.

Ditinjau dari aspek syarat teknis penuntun praktikum berbasis model pembelajaran Collaborative Teamwork Learning (CTL) dinyatakan valid oleh oleh validator dengan nilai rata-rata 82,29 $\%$. Kriteria tersebut terpenuhi karena penuntun praktikum berorientasi gambar yang dikembangkan dapat meningkatkan minat siswa dalam melakukan praktikum karena penuntun praktikum dilengkapi dengan warna dan gambar yang menarik sesuai dengan aslinya. Hal ini sesuai dengan yang dinyatakan oleh Rohman dan Amri (2013:105) bahwa warna merupakan unsur tambahan yang sangat penting dalam media gambar, dapat memberikan penekanan, pemisahan dan kesatuan.

Ditinjau dari aspek syarat bahasa penuntun praktikum berbasis model pembelajaran Collaborative Teamwork
Learning (CTL) dinyatakan valid oleh oleh validator dengan nilai rata-rata 89,58 $\%$. Hal ini menunjukkan bahwa penulisan penuntun praktikum menggunakan bahasa yang telah sesuai dengan kaidah bahasa indonesia yang benar dan baik serta menggunkan kalimat yang singkat, padat dan jelas agar siswa mudah memahami penunutun praktikum tersebut. Penulisan penuntun praktikum menurut Prastowo (2011:89) usahakan agar kalimat yang digunakan tidak terlalu panjang dan menggunakan kalimat yang sederhana, namun jumlah kalimat perparagrafnya sekitar 3-4 kalimat.

\section{IMPLIKASI}

Berdasarkan penelitian yang dilakukan penuntun praktikum berbasis model pembelajaran Collaborative Teamwork Learning (CTL) dapat disimpulkan bahwa penuntun praktikum dikembangkan dengan model pengembangan 3D adaptasi dari 4D pada materi sistem organisasi kehidupan kelas VII SMP melalui uji validasi dengan instrumen lembar penilaian mendapat nilai rata-rata $84,98 \%$ dengan kategori valid berdasarkan aspek syarat didaktik, syarat konstruk, syarat teknis dan syarat bahasa dengan revisi kecil dan layak digunakan dalam kegiatan praktikum di sekolah.

\section{REFERENSI}

Arsyad, A. 2013. Media Pembelajaran. Jakarta: Rajawali Pers.

Jiwa, Wayan Merta, Atmadja, Nengah Bawa \& Yudana, Made. 2013. Pengaruh Model Collaborative Teamwork Learning terhadap Motivasi dan Prestasi Belajar Sosiologi Siswa Kelas X SMA Negeri 1 Amlapura. E-Journal Pendidikan Ganesha Volume 4 Nomor 3 Halaman 119-126.

Purwanto, M. N. 2010. Prinsip-prinsip dan Teknik Evaluasi Pengajaran. Bandung: Remaja Rosdakrya. 
Purnamasari (2012). Penuntun Praktikum. Jakarta: Prestasi Pustakaraya.

Prastowo, A. 2011. Panduan Kreatif Membuat Bahan Ajar Inovatif. Yogyakarya:DIVA Press.

Rohman dan Amri. 2013. Strategi dan Desain Pengembangan Sistem Pembelajaran. Jakarta: Prestasi Pustakaraya.

Susantini, E. 2012. Pengembangan Petunjuk Praktikum Genetika Untuk Melatih Keterampilan Berfikir Kritis. Jurnal Pendidikan IPA Indonesia. Hal $1-13$.
Trianto. 2010. Mengembangkan Model Pembelajaran Tematik. Jakarta: PT.Prestasi Pustakaraya

Widayanti, F. W., Slamet., dan Masduki. 2011. Peningkatan Motivasi Belajar Siswa pada Pembelajaran Matematika Melalui Metode Collaborrative Learning dengan Memanfaatkan Microsoft Powerpoint 2007. Prosiding Seminar Nasional Matematika Prodi Pendidikan Matematika, Universitas Muhammadiyah Surakarta, 25 Juli 2011:128. 